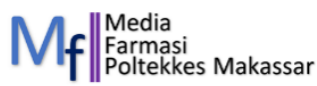

\title{
PERANAN APOTEKER DALAM PEMBERIAN INFORMASI OBAT DI INSTALASI FARMASI RUMAH SAKIT UMUM DAERAH HAJI ANDI SULTHAN DAENG RADJA KABUPATEN BULUKUMBA
}

\author{
Santi Sinala ${ }^{1}$ \\ ${ }^{2}$ Jurusan Farmasi Poltekkes Kemenkes RI Makassar \\ *) E-mail korespondensi :santisinala1983@gmail.com
}

DOI: https://doi.org/10.32382/mf.v13i2.882

\begin{abstract}
ABSTRAK
Pelayanan Informasi Obat (PIO) di rumah sakit sangat diperlukan oleh pasien untuk memberikan jaminan pengobatan rasional, efektif, dan aman. Dengan terlaksananya PIO sangat menguntungkan bagi pasien maupun pihak rumah sakit. Tujuan penelitian ini untuk memperoleh informasi tentang peranan apoteker sebagai pemberi informasi obat di Instalasi Farmasi Rumah Sakit Umum Daerah Haji Andi Sulthan Daeng Radja Kabupaten Bulukumba. Penelitian ini dilaksanakan di Instalasi Farmasi Rumah Sakit Umum Daerah Haji Andi Sulthan Daeng Radja Kabupaten Bulukumba pada bulan April-Mei 2017. Jenis penelitian adalah deskriptif. Jumlah sampel sebanyak 100 pasien. Pengambilan sampel menggunakan teknik random sampling. Instrumen yang digunakan dalam penelitian ini yaitu kuesioner. Hasil penelitian menunjukkan bahwa peranan apoteker dalam pemberian informasi obat di Instalasi Farmasi Rumah Sakit Umum Daerah Haji Andi Sulthan Daeng Radja Kabupaten Bulukumba termasuk dalam kategori sangat baik $(81,53 \%)$.
\end{abstract}

\section{Kata kunci : Peranan apoteker, PIO}

\section{PENDAHULUAN}

Kesehatan merupakan kebutuhan dasar manusia untuk dapat hidup layak dan produktif, untuk itu diperlukan penyelenggaraan pelayanan kesehatan yang terkendali biaya dan kualitasnya (Kemenkes RI, 2012).

$\begin{array}{llr}\text { Rumah } & \text { sakit adalah institusi } \\ \text { pelayanan } & \text { kesehatan } & \text { yang }\end{array}$ menyelenggarakan pelayanan kesehatan perorangan secara paripurna yang menyediakan pelayanan rawat inap, rawat jalan, dan gawat darurat (Permenkes 58, 2014).

Tuntutan pasien dan masyarakat akan peningkatan mutu pelayanan kefarmasian, mengharuskan adanya perluasan dari paradigma lama yang berorientasi kepada produk (drug oriented) menjadi paradigma baru yang berorientasi pada pasien (patient oriented) dengan filosofi Pelayanan Kefarmasian (pharmaceutical care).

Karena adanya tuntutan tersebut, tenaga kefarmasian juga diharuskan untuk memberikan (Pelayanan Informasi Obat) PIO. PIO di rumah sakit sangat diperlukan oleh pasien untuk memberikan jaminan pengobatan yang rasional, efektif dan aman. Menurut peraturan menteri kesehatan republik Indonesia Nomor 58 Tahun 2014 tentang standar pelayanan kefarmasian dirumah sakit, (Pelayanan Informasi Obat) PIO merupakan kegiatan penyediaan dan pemberian informasi, rekomendasi obat yang independen, akurat, tidak bias, terkini dan komprehensif yang dilakukan apoteker kepada dokter, apoteker, perawat, profesi kesehatan lain diluar rumah sakit. Dengan terlaksananya PIO sangat menguntungkan bagi pasien maupun pihak rumah sakit. Apotek adalah sarana pelayanan kefarmasian tempat dilakukan praktek kefarmasian oleh apoteker (Peraturan Pemerintah No.51 Tahun 2009). Apoteker sebagai pelaku utama pelayanan kefarmasian yang bertugas sebagai pelaksana atau pemberi pelayanan kesehatan diberi wewenang sesuai kompetensi pendidikan yang diperolehnya, sehingga terkait erat dengan hak dan kewajiban.

Pelayanan kesehatan yang bermutu merupakan salah satu tolak ukur kepuasan pasien yang berefek terhadap keinginan 
pasien untuk kembali kepada institusi pelayanan yang memberikan pelayan kesehatan yang bermutu, professional, ramah, ikhlas, bermutu dan antusias, termaksud pelayanan kefarmasian pada saat ini telah berubah orientasinya dari obat kepada pasien yang mengacu pada pharmaceutical care (asuhan kefarmasian). Sebagai konsekuensi perubahan orientasi tersebut, apoteker dituntut untuk meningkatkan pengetahuan, keterampilan dan perilaku agar dapat berinteraksi langsung dengan pasien. Sebagai upaya agar dapat melaksanakan pelayanan kefarmasian yang profesional.

Berdasarkan hasil observasi awal di rumah sakit umum daerah (RSUD) Haji Andi Sulthan Daeng Radja Kabupaten Bulukumba, menujukan bahwa pasien sebagai konsumen yang dilayani di apotek rumah sakit, berinteraksi dengan apoteker hanya dengan cara menyerahkan resep, lalu menerima obatnya. Masih ada pasien yang belum terlalu memahami tentang obat yang diberikan oleh apoteker, padahal informasi obat merupakan hak pasien. Oleh Karen itu peneliti tertarik ingin melakukan penelitian yang berkaitan dengan peranan apoteker dalam memberikan informasi tentang obat yang diserahkan kepada pasien di RSUD Haji Andi Sulthan Daeng Radja Kabupaten Bulukumba.

Rumusan masalah yang muncul yaitu bagaimana peranan apoteker dalam memberikan pelayanan informasi obat di Instalasi Farmasi RSUD Haji Andi Sulthan Daeng Radja Kabupaten Bulukumba. Tujuan penelitian ini adalah untuk memperoleh informasi tentang peranan apoteker sebagai pemberi informasi obat di Instalasi Farmasi RSUD Haji Andi Sulthan Daeng Radja Kabupaten Bulukumba.

\section{METODE DAN BAHAN \\ Jenis Penelitian}

Jenis penelitian ini adalah deskriptif dengan teknik pengumpulan data menggunakan kuesioner yang diberikan kepada pasien rawat jalan di RSUD Haji Andi Sulthan Daeng Radja Kabupaten Bulukumba.

\section{Tempat dan Waktu Penelitian}

Penelitian ini telah dilaksanakan di Instalasi Farmasi RSUD Haji Andi Sulthan Daeng Radja Kabupaten Bulukumba, pada bulan April- Mei 2017.

\section{Populasi dan Sampel}

1. Populasi

Populasi dalam penelitian ini adalah pasien rawat jalan yang menebus obat di Instalasi Farmasi Rawat Jalan RSUD Haji Andi Sulthan Daeng Radja Kabupaten Bulukumba. Dimana jumlah kunjungannya pada tahun 2016 berjumlah 67.140 pasien/tahun dan ratarata 5595 pasien/bulan.

2. Sampel

Sampel dihitung berdasarkan Rumus Slovin dengan tingkat kesalahan $10 \%$

Dimana :

$$
\text { Rumus Slovin : } \mathrm{n}=\frac{N}{1+N d^{2}}
$$

$$
\begin{aligned}
& \mathrm{n}=\text { Sampel } \\
& \mathrm{N}=\text { Populasi } \\
& \mathrm{d}=\text { Tingkat kesalahan }(0,1)
\end{aligned}
$$

Adapun penarikan sampel menggunakan teknik random sampling.

\section{Teknik Pengumpulan dan Pengolahan}

Data

1. Pengumpulan Data

a. Data dikumpulkan berdasarkan hasil jawaban responden atas pertanyaan-pertanyaan dalam kuesioner

b. Setiap pertanyaan dalam kuesioner disediakan tiga pilihan jawaban, yaitu (1) selalu (2) kadang-kadang (3) Tidak pernah.

2. Teknik Pengolahan Data

Teknik yang digunakan dalam pengolahan data adalah berdasarkan fakta dan data yang diperoleh langsung di lapangan,yakni dengan mengumpulkan hasil jawaban dari kuesioner, kemudian ditabulasi, diskoring, dan dipresentasikan. Cara pengukuran menggunakan Skala likert (Sugiyono,2013).

Skor untuk jawaban selalu (sangat baik) $=3$ Skor untuk jawaban kadang-kadang (baik) $=2$ Skor untuk jawaban tidak pernah (kurang) $=1$

Persentase skor $=\frac{\text { Jumlah skor rata }- \text { rata }}{\text { skor ideal }} \times 100 \%$

Skor ideal $=$ Jumlah responden $\mathrm{x} 3$ (Skor tertinggi)

Jawaban yang diperoleh berdasarkan presentase skor dibagi atas tiga kategori, yaitu :

$33,3 \%-55,5 \%=$ kurang baik 
$55,6 \%-77,7 \%=$ Baik

$77,8 \%-100 \%=$ Sangat baik

\section{HASIL DAN PEMBAHASAN}

\section{Hasil Penelitian}

Pengumpulan data penelitian mengenai peranan Apoteker dalam pemberian informasi di Instalasi farmasi RSUD Haji Andi Sulthan Daeng Radja
Kabupaten Bulukumba pada bulan AprilMei tahun 2017, dengan jumlah responden 100 orang yang dipilih dengan teknik random sampling.

\section{a. Karakteristik Responden}

Identitas responden dibagi dalam tiga kategori, yaitu berdasarkan jenis kelamin, umur, dan pekerjaan.

Tabel 1. Karakteristik Responden

\begin{tabular}{|c|c|c|c|}
\hline No & Variabel & Jumlah Responden & Persentase $(\%)$ \\
\hline \multirow[t]{3}{*}{1} & Jenis kelamin & & \\
\hline & a. Laki-laki & 38 & 38 \\
\hline & b. Perempuan & 62 & 62 \\
\hline \multirow[t]{4}{*}{2} & Umur (Tahun) & & \\
\hline & a. $17-37$ & 56 & 56 \\
\hline & b. $38-58$ & 37 & 37 \\
\hline & c. $59-78$ & 7 & 7 \\
\hline \multirow[t]{8}{*}{3} & Pekerjaan & & \\
\hline & a. Mahasiswa & 10 & 10 \\
\hline & b. Pegawai Negeri Sipil & 14 & 14 \\
\hline & c. Tenaga honorer & 11 & 11 \\
\hline & d. Petani & 8 & 8 \\
\hline & e. Wiraswasta & 23 & 23 \\
\hline & f. Pensiunan & 2 & 2 \\
\hline & g. Ibu Rumah Tangga & 32 & 32 \\
\hline
\end{tabular}

\section{b. Jawaban responden}

Data dari hasil jawaban kuesioner yang ditujukan kepada 100 orang responden, diakumulasi berdasarkan jawaban selalu, kadang-kadang, dan tidak pernah. Adapun hasil jawaban responden dapat dilihat pada tabel di bawah ini

Tabel 2 : Peranan Apoteker Dalam Pemberian Informasi Obat Di Instalasi Farmasi Rumah Sakit Umum Daerah Haji Andi Sulthan Daeng Radja Kabupaten Bulukumba.

\begin{tabular}{|c|c|c|c|c|c|c|c|c|}
\hline \multirow{3}{*}{ Butir soal } & \multicolumn{2}{|c|}{ A } & \multicolumn{2}{|c|}{ B } & \multicolumn{2}{|c|}{ C } & \multirow{2}{*}{\multicolumn{2}{|c|}{ Jumlah }} \\
\hline & \multicolumn{2}{|c|}{ Selalu } & \multicolumn{2}{|c|}{ Kadang-kadang } & \multicolumn{2}{|c|}{ Tidak pernah } & & \\
\hline & Jwb & Skor & Jwb & Skor & Jwb & Skor & Jwb & Skor \\
\hline 1 & 52 & 156 & 48 & 96 & 0 & 0 & 100 & 252 \\
\hline 2 & 78 & 234 & 20 & 40 & 2 & 2 & 100 & 276 \\
\hline 3 & 67 & 201 & 30 & 60 & 3 & 3 & 100 & 264 \\
\hline 4 & 52 & 156 & 46 & 92 & 2 & 2 & 100 & 250 \\
\hline 5 & 14 & 42 & 44 & 46 & 42 & 42 & 100 & 130 \\
\hline 6 & 25 & 75 & 33 & 66 & 42 & 42 & 100 & 183 \\
\hline 7 & 60 & 180 & 33 & 66 & 7 & 7 & 100 & 253 \\
\hline 8 & 76 & 228 & 23 & 46 & 1 & 1 & 100 & 275 \\
\hline 9 & 69 & 207 & 30 & 60 & 1 & 1 & 100 & 268 \\
\hline 10 & 55 & 167 & 43 & 86 & 2 & 2 & 100 & 253 \\
\hline Jumlah & 548 & 1644 & 350 & 700 & 102 & 102 & 1000 & 2404 \\
\hline Rata-rata & 54,8 & 164,4 & 35 & 70 & 10,2 & 10,2 & 100 & 240,4 \\
\hline $\begin{array}{c}\text { Presentase } \\
\text { Skor }\end{array}$ & \multicolumn{2}{|c|}{$54,8 \%$} & \multicolumn{2}{|c|}{$23,33 \%$} & \multicolumn{2}{|c|}{$3,4 \%$} & \multicolumn{2}{|c|}{$81,53 \%$} \\
\hline
\end{tabular}




\section{Pembahasan}

Pelayanan informasi obat di Instalasi Farmasi RSUD Haji Andi Sulthan Daeng Radja Kabupaten Bulukumba merupakan salah satu hal yang sangat dibutuhkan oleh masyarakat yang datang berobat ke rumah sakit tersebut. Dalam hal ini apoteker harus mampu memberikan informasi dengan jelas, tepat dan akurat perihal obat yang diberikan. Untuk menilai sejauh mana peran apoteker dalam pelayanan informasi obat kepada pasien yang datang menebus obat di Instalasi Farmasi RSUD Haji Andi Sulthan Daeng Radja Kabupaten Bulukumba, maka telah diperoleh hasil jawaban penelitian dari 100 responden yang dipilih secara acak.

Berdasarkan tabel 2 di atas dapat dilihat pada pertanyaan ke-1, 52 responden menyatakan selalu dan 48 responden kadangkadang. Hal ini menunjukkan bahwa tidak selalu apoteker memberikan penjelasan menegenai obat yang diberikan kepada pasien di Instalasi Farmasi RSUD Haji Andi Sulthan Daeng Radja Kabupaten Bulukumba.

Untuk pertanyaan ke-2 tentang pemberian penjelasan mengenai aturan pakai, 78 responden menyatakan selalu, 20 responden kadang-kadang, dan 2 responden menyatakan tidak pernah. Hal ini menunjukkan kebanyakan responden sudah diberikan penjelasan mengenai aturan pakai.

Pada pertanyaan ke-3 mengenai waktu penggunaan obat, 67 responden menyatakan selalu, 30 responden menyatakan kadang-kadang, 3 responden menyatakan tidak pernah. Hal ini menunjukkan bahwa apoteker tidak selalu memberikan penjelasan mengenai waktu penggunaan obat, disebabkan karena pasien yang datang berobat adalah pasien berulang.

Untuk pertanyaan ke-4 mengenai penjelasan tentang cara pemakaian obat, 52 responden menyatakan selalu, 46 responden menyatakan kadang-kadang, 2 responden menyatakan tidak pernah mendapat penjelasan tentang cara pemakaian obat. Hal ini menunjukkan bahwa apoteker tidak selalu memberikan penjelasan mengenai cara pemakaian obat, disebabkan karena cara pemakaian obat hanya dilakukan pada obat tertentu.

Berdasarkan pertanyaan ke-5 mengenai pemberian penjelasan mengenai efek samping obat, 14 responden menyatakan selalu, 44 responden menyatakan kadangkadang, dan 42 responden menyatakan tidak pernah diberikan penjelasan tentang efek samping obat oleh apoteker. Hal ini mungkin disebabkan karena efek samping obat sudah ada tertera dalam brosur obat sehingga hanya obat yang tidak memiliki brosur yang dijelasakan efek sampingnya.

Untuk pertanyaan ke-6 mengenai cara/tempat penyimpanan obat yang benar, 25 responden menyatakan selalu, 33 responden menyatakan kadang-kadang, 42 responden menyatakan tidak pernah diberikan informasi mengenai penyimpanan obat yang benar. Hal ini dikarenakan mungkin banyaknya pasien yang datang berobat, sehingga apoteker tidak sempat memberikan informasi mengenai penyimpanan obat yang benar kepada semua pasien.

Pada pertanyaan ke-7 tentang apoteker menjawab pertanyaan yang responden ajukan mengenai obat yang diberikan, 60 responden menyatakan selalu, 33 responden menyatakan kadang-kadang, dan 7 responden menyatakan tidak pernah apoteker menjawab pertanyaan yang pasien ajukan menegenai obat yang diberikan.hal ini menunjukkan bahwa apoteker hampir selalu memberikan penjelasan jika ada pasien yang bertanya tentang obat yang diberikan.

Berdasarkan pertanyaan ke-8 tentang pemahaman pasien terhadap penjelasan yang diberikan oleh apoteker, 76 responden menyatakan selalu, 23 responden menyatakan kadang-kadang, dan 1 responden menyatakan tidak pernah memahami penjelasan yang diberikan oleh apoteker. Hal ini menujukkan hampir semua apoteker sudah memberikan penjelasan yang baik kepada pasien.

Untuk pertanyaan ke-9 tentang apoteker bersifat sopan dan ramah dalam melayani responden, 69 responden menyatakan selalu, 30 responden menyatakan kadang-kadang, dan 1 responden menyatakan tidak pernah apoteker bersifat sopan dan ramah dalam melayani pasien.

Pada pertanyaan ke-10 mengenai responden merasa senang dengan pelayanan yang diberikan apoteker, 55 responden menyatakan selalu, 43 responden menyatakan kadang-kadang, dan 2 responden menyatakan tidak pernah merasa senang dengan pelayanan yang diberikan apoteker. 
Hal ini dikarenakan karena beratnya tugas apoteker sehingga menyebabkan apoteker kurang terbuka dalam melayani pasien.

Secara kumulatif diperoleh persentase skor dari 100 orang responden yang menjawab selalu $(54,8 \%)$, kadangkadang $(23,33 \%)$, dan tidak pernah $(3,4 \%)$. Hasil persentase tersebut menunjukkan bahwa responden yang menyatakan selalu memperoleh informasi obat dari apoteker lebih tinggi dibanding dengan responden yang menyatakan kadang-kadang dan tidak pernah.

Sekalipun data yang diperoleh menunjukkan bahwa cukup banyak responden $(54,8 \%)$ yang memberikan jawaban pada opsi selalu, tetapi tetap saja ada responden yang menjawab kadang-kadang $(23,33 \%)$ dan tidak pernah $(3,4 \%)$ memperoleh informasi obat dari apoteker. Hal ini harus menjadi perhatian apoteker di instalasi farmasi rumah sakit umum daerah Haji Andi Sulthan Daeng Radja Kabupaten Bulukumba untuk meningkatkan pelayanan informasi obat, sehingga seluruh pasien dapat memperoleh informasi obat yang dibutuhkannya.

Berdasarkan persentase skor total responden dapat disimpulkan bahwa peranan apoteker dalam pemberi informasi obat di Instalasi Farmasi RSUD Haji Andi Sulthan Daeng Radja Kabupaten Bulukumba termaksud dalam kategori sangat baik $(81,53 \%)$. Hasil penelitian ini diharapkan menjadi masukan kepada apoteker di Instalasi Farmasi RSUD Haji Andi Sulthan Daeng Radja Kabupaten Bulukumba maupun apoteker di sarana pelayanan kesehatan lainnya, untuk memperhatikan pelayanan informasi obat kepada pasien. Hal ini akan mempengaruhi pemahaman pasien dalam penggunaan obat yang benar sehingga pengobatan menjadi rasional

\section{PENUTUP}

\section{Kesimpulan}

Berdasarkan hasil penelitian dan pembahasan yang telah diuraikan, maka dapat disimpulkan bahwa peranan apoteker dalam pemberian informasi obat di Instalasi Farmasi RSUD Haji Andi Sulthan Daeng Radja Kabupaten Bulukumba pada tahun2017 termaksud dalam kategori sangat baik $(81,53 \%)$.

\section{Saran}

Diharapkan apoteker lebih meningkatkan pelayanan informasi obat kepada pasien karena belum semua pasien menerima pelayanan informasi obat.

\section{DAFTAR PUSTAKA}

Kemenkes RI, (2009). Tentang KesehatanUU No 36 Tahun2009, Jakarta: Kedokteran EGC, Jakarta.

Kemenkes RI, (2012). Buku Pegangan Sosialisasi Jaminan Kesehatan Nasional (JKN) dalam Sistem Jaminan Sosial Nasional, Jakarta : Kementerian Kesehatan Republik Indonesia.

Kemenkes RI, (2014). Peraturan Menteri Kesehatan Republik Indonesia Nomor 58 Tahun 2014 Tentang Standar Pelayanan Kefarmasian di Rumah Sakit.

Sugiyono, ( 2013). Metode Penelitian Pendidikan (Pendidikan kuantitatif, kualitatif, dan R \& D), Alfabet, Bandung

Surahman.M.E., dan Husen. R.I., (2011). Pharmaceutical Care, Penerbit Widya Padjadjaran Yogyakarta 